\title{
Risk Factors of HIVIAIDS Among Secondary and Preparatory School Students in Dire Dawa City, Ethiopia
}

\author{
Dawit Daniel $^{1}$, Zinabe Seyoum ${ }^{2}$, Alemusa Gipo ${ }^{2}$ \\ ${ }^{1}$ Department of Statistics, Dire Dawa University, Dire Dawa, Ethiopia \\ ${ }^{2}$ Department of Psychology, Dire Dawa University, Dire Dawa, Ethiopia
}

Email address:

davedan8@gmail.com (D. Daniel)

To cite this article:

Dawit Daniel, Zinabe Seyoum, Alemusa Gipo. Risk Factors of HIV/AIDS Among Secondary and Preparatory School Students in Dire Dawa City, Ethiopia. American Journal of Health Research. Vol. 5, No. 3, 2017, pp. 83-92. doi: 10.11648/j.ajhr.20170503.15

Received: March 21, 2017; Accepted: April 1, 2017; Published: June 22, 2017

\begin{abstract}
Youth are exposed to risk behavior which includes unsafe sex, drug abuse \& alcohol and also there are different factors which are associated with their risk behaviors. The main objective of this study is to identify behavioral risk factors for HIV/AIDS among high school students of Dire Dawa city. A cross-sectional school-based design using stratified random sampling technique was employed. Data collection was done using self-administered questionnaire among 840 adolescent high school students. Data analysis involved univariate analysis, bivariate analysis followed by multiple logistic regression analysis to identify determinants of unsafe sexual practice. The findings revealed that $392(48.3 \%)$ of respondents had sex. The mean age at first sex was 16.6(+0.84) and 15.6(+0.9) years for males and females respectively. The risk of unsafe sex was high among male students $[\mathrm{AOR}=13.176,95 \% \mathrm{CI}(3.894,44.586)]$ and those using substance \& alcohol $[\mathrm{AOR}=2.098,95 \% \mathrm{CI}$ $(1.386,3.17)]$ whereas the risk was less among students not watching pornography $[\mathrm{AOR}=0.098,95 \% \mathrm{CI}(0.023,0.419)]$ and earning better income $[\mathrm{AOR}=0.85,95 \% \mathrm{CI}(0.025,0.289)]$. Female students started sexual practice earlier than their male counterpart and half of the students are engaged on unsafe sex which requires urgent intervention. Therefore stakeholders has to increase connections between students and their schools through the use of media. Furthermore they should work towards making communities safe and supportive for youth development.
\end{abstract}

Keywords: Adolescents, Risky Behaviors, HIV/AIDS, Dire Dawa, Ethiopia

\section{Introduction}

The rapid expansion of HIV/AIDS in sub-Saharan countries has a profound impact on the health sector as well as the socio-economic development and education of the region. Sub-sahra Africa is the most affected part of the world where more than two thirds of all people with HIV/AIDS are living. In worst affected countries the pandemic has reversed the developmental gains of the past few decades, including the hard-won increase in child survival and gains in life expectancy. The HIV/AIDS situation in Ethiopia has evolved from two reported cases in 1986 to a cumulative total of 147,000 by mid-2003 but the vast majority are unreported and many more have died unnoticed and unaided (MOH, 2004, AIDS in Ethiopia). In 2004 it was estimated that 1.5 million people were living with HIV/AIDS and in 2011 DHS it has been found out that the prevalence was 1.5 for both sex where females having prevalence rate of 1.9 whereas males 1.0 with clear indication of variation of the distribution of the disease with sex. Place of residence based prevalence was also varied from 4.2 in urban to 0.6 in rural. The estimates from the Federal Ministry of Health $(\mathrm{MOH})$ and Federal HIV/AIDS Prevention and Control Office (HAPCO) UNAIDS suggest an HIV adult prevalence of $2.2 \%$, and prevalence among 15 to 24 year olds at 5.6 percent. Previous studies conducted among this age group in Ethiopia have shown that those engaging in sexual contact report multiple partners, nonconsistent condom use, and sexual contact with commercial sex workers. University students clearly fall within this age range. All of these are behaviors that increase the likelihood of contracting HIV. That is the HIV/AIDS epidemic is at a stage in Ethiopia that it may threaten many of the underlying health, social and economic sectors. What is less understood are the specific dimensions of the epidemic for various 
sectors of the Ethiopian economy and society. Foremost among these sectors is education. As one of the fundamental and largest social service sectors as well as the basis for social and economic development, any threat to education will have grave consequences beyond the education sector. The Youth Risk Behavior Survey (YRBS) which is also called youth Risk Behavior Surveillance System is the primary survey tool developed by the Centers for Disease Control and Prevention (CDC) to aid communities in defining and measuring risk behaviors of youth. This survey tool, which has proven reliability, is widely used in most part of the world. The YRBS was developed with three main goals of focusing on specific behaviors among youth that cause important health problems, determining whether those behaviors increase, decrease, or remain the same over time; and provide comparable data among national and local samples of youth [1].

Adolescents are exposed are exposed to risk behavior which includes unsafe sex, drug abuse\& alcohol and also there are different factors which are associated with their risk behaviors. Thus, there is a need to firmly assess the issue of adolescents' risky behaviors; since it is a multidimensional construct comprised of heterogeneous psychological and social factors. Additionally factors such as parent's socioeconomic status have been identified as influencing adolescents' health behavior. More than half of all new HIV infections occur in 15 to 24 years olds. Members of this age group feel less susceptible to adverse outcomes associate with risk behaviors and are therefore at greater risk for HIV/AIDS. Due to their age range high school students are among this highly subjected group to different risky behaviors. A study conducted among high school students in Gondar showed that $16.7 \%$ of students reported to have had Sexual contact with commercial sex worker or non-regular partner and out of 84 sexually active students $54.8 \%$ did not use condoms [2]. A research conducted in Dire-Dawa University indicated that about $78 \%$ of the students started sex before coming to the university [3]. From those reported as starting sex before joining the university $91 \%$ were women which signals the alarming exposure in their high school stay. A study conducted among high school students in Addis Ababa indicated that $32 \%$ of the students rated themselves at risk of HIV infection and $35.2 \%$ were not willing to disclose their HIV positive status [4]. Another similar study conducted in Addis Ababa reported that $53 \%$ of men and $24 \%$ of women were sexually active students and argued that since these students are highly likely to have more than one sexual partner they are at high risk of contracting the disease [5].

Therefore the general objective of this study is to assess level of parental monitoring of students and behavioral risk factors for HIV/STI. The specific objectives are:

a) To assess sexual practice across sex of students

b) To identify determinants of students' ever having sexual practice behaviors

c) To identify determinants of unsafe sex among Dire Dawa high school students

\section{Literature Review}

On these days, researchers carry out such an earth shaking researches to identify the determinant factors of adolescents' risky behaviors. They give emphasis to know what determines adolescents' behavioral traits such as risky sexual behaviors, alcohol and drug addictions, school dropouts, poor academic performance, aggressiveness, assertiveness and so forth. Some are focusing on the role of heredity and others are focusing on the role of environment such as family interaction with their children.

\subsection{General and Prevalence}

Although several studies on KAP on HIV/AIDS have been conducted in different parts of Ethiopia among diverse population groups (6-14), except this study no single study had examined HIV sero prevalence in association with KAP of the respondents. However, an earlier study involving elementary school students of age 10-14 years in a rural small town of Amhara region showed HIV prevalence of $1.4 \%$. Interestingly, the $1.1 \%$ sero prevalence of HIV observed among the participants in the present study is one of the lowest ever reported from any population group from the country. Although, there is no data on HIV sero prevalence among high school students in the study area, our previous reports from Gondar indicated very high prevalence of HIV ranging from over $50 \%$ in tuberculosis patients, and $5 \%$ in rural and elderly cataract patients. In view of the high prevalence of HIV observed in the different population groups in the region, the $1.1 \%$ prevalence of HIV observed among high school students in Gondar is very low. However, considering the young ages and the female majority among the seropositive $(66.7 \%)$, HIV infection is still a threat to the generation. In that study, the prevalence of HIV was higher among students who chew chat, drink alcohol and smoke cigarette as compared to non-chewer, non-drinker and nonsmokers counterparts. Considerable proportions of the respondents had adequate knowledge about the common ways of transmission and prevention of the infection. This is an encouraging finding which should further be strengthened by establishing organizing HIV/AIDS Clubs in those areas. The findings that over a fourth of the sexually active respondents had multiple sexual partners including CSWs indicate that such risky behavior can predispose the students to acquisition of STDs including HIV. Furthermore, condoms were used only some times by about a third of those who were practicing sexual intercourse. It is worth noting that only about $42 \%$ of the respondents believed use of condom as a means to prevent transmission of HIV. In summary, the prevalence of HIV infection is low among high school students in Gondar. In addition, even though the majority of the students had adequate knowledge about HIV/AIDS and VCT, their perception of risk of acquisition and practice of protected sex is low. These call for continued and strengthened health education to bring behavioral changes among the students [6]. 


\subsection{Comprehensive Knowledge}

Family wealth index was associated with comprehensive HIV/AIDS knowledge, in that adolescents from a middle or high family wealth index were more likely to have comprehensive HIV/AIDS knowledge compared to those from a low family wealth index (AOR $[95 \% \mathrm{CI}]=1.39[1.03-$ 1.87] and 1.75 [1.24-2.47], respectively). The family wealth index effect was stronger and significant for adolescents from families in rural areas compared to those from families in urban areas (COR and [95\% CI] $=2.00$ [1.24-3.20]; and 1.38 [0.77-2.45], respectively). The major sources of information on HIV/AIDS were associated with comprehensive HIV/AIDS knowledge. Adolescents who reported friends or mass media as their major sources were more likely to have comprehensive HIV/AIDS knowledge compared to those who cited family members as their major source (AOR [95\% $\mathrm{CI}]=1.63[1.17-2.27]$ and $1.55[1.14-2.11]$, respectively). Adolescents who reported that they had been taught about HIV/AIDS and the related topics at school were 1.59 times more likely to have comprehensive HIV/AIDS knowledge compared to those who did not report being taught on such topics (AOR [95\% CI] $=1.59$ [1.22-2.08]). Discussion on sexual matters with parents or other family members was not associated with comprehensive HIV/AIDS knowledge (AOR $[95 \% \mathrm{CI}]=1.01[0.81-1.25])[6]$.

This study suggests that the education system needs to implement specific and focused educational programs for students in school prior to collage admission and promote health promotion. It is important that school students understand HIV prevention and transmission, as well as develop positive attitude and good practice. The school is a good place and time to have peer education programs that address self-esteem, healthy sexual attitudes, as well as to be socially active, accepting and caring. Taking into consideration the fact that not all students are sexually active, developing messages geared towards them while offering strategies that help students delay sex, refuse sex, or negotiate safer sexual practices should be included. This program must give students an understanding of why it is more advantageous to abstain from sex without promoting unnecessary fear [6].

Only six students were found to be infected with HIV putting its prevalence at $1.1 \%$. Half of them responded that they did not practice sex. The majority $(97.5 \%)$ of the participants responded that $\mathrm{HIV}$ is an etiologic agent for AIDS. Unprotected sex, unsafe blood transfusion, contaminated needles and mother to child transmissions were reported by $84.6 \%, 64.2 \%, 78.8 \%$, and $69 \%$ of the students as the common ways of HIV transmission. Only $3.6 \%$ reported mosquito bite $(2.5 \%)$, shaking hands $(0.7 \%)$ and eating and drinking with infected individuals $(0.4 \%)$ as mode of HIV transmission. Abstinence, faithfulness to one's partner and use of condom as means to prevent transmission of HIV was responded by $84.1 \%, 60.4 \%$ and $41.8 \%$ of the students, respectively. Avoiding social life with AIDS patients was reported by $1.8 \%$ of the respondents as a way to prevent transmission of HIV [1]. The majority of students surveyed were aware that HIV can be transmitted by sexual intercourse $(97.7 \%)$, from mother to child $(88.3 \%)$ and through sharing needles or syringes $(92.0 \%)$. Misconceptions about transmission of HIV were observed among 59.3\% to $74.3 \%$ of respondents [6].

The Addis Ababa Administration Education Bureau reported practices of transactional sex in secondary schools. It mentioned low level of awareness and lack of information on sexuality, STI and HIV and AIDS as major factors for early and unprotected sexual practices. For example, a study by the same bureau on KAP of reproductive health and HIV and AIDS among selected secondary school students in Addis Ababa indicated that young students had limited information compared to older ones. Such low level of awareness and knowledge deprive them of the chances of avoiding risky sexual practices. Two major factors that contribute to the severity of the problem as cited by the focal person include lack of adequate information to address reproductive health issues in the school curriculum and cultural prohibition of discussions about sex and sexuality within the family. As a result, children reach teenage maturity without getting proper orientation on sex, sexuality and issues of reproductive health; and at the time of sexual debut; they would be forced to face the consequences. The AAAEB focal persons reported that students, especially, those in the secondary level have sexual debut quite earlier than they joined HEIs. Some studies attribute the early age sexual debut to peer pressure, nutritional conditions and exposure to pornographic information obtained from the Internet and other media [7].

\subsection{Risky Behavior Sex Related}

In a research which was done in Gondar town it was seen that $25 \%$ of all respondents had at least one risk behavior related to HIV \& other STIs transmission. $65 \%$ of male and $35 \%$ of female already initiated sexual intercourse at mean age of 17.3 and 17.1 years respectively. About $39 \%$ reported having unprotected sex (sex without condom); $43.3 \%$ of sexually active students had more than one sexual partner; $5 \%$ reported having sex with sex workers; $15 \%$ reported having sex under the influence of alcohol; 31.7\% undergo sexual intercourse in unusual route and 5\% shared sharps. Further analysis indicated significantly more risk behaviors that can predispose students to HIV and other STIs were practiced in male, alcohol users and drugs abusers $(p<0.05)$. However; practicing risk behavior among students did not significantly varies with respect to their knowledge, attitude and socio economic status. The findings that over $40 \%$ of the sexually active respondents had multiple sexual partners including commercial sex workers indicate such risky behavior can predispose the students to acquisition of STDs including HIV. Furthermore; condoms were used only some times by about a third of those who were undergoing sexual intercourse. In practice, sexually active students are still shy to buy condom because of religious and socio-cultural norms related to youths, especially unmarried youths. It is worth 
noting that about $30 \%$ of sexually active students undergo sexual intercourse under the influence of alcohol and drugs of abuse and $31.7 \%$ undergoes through an unusual route. Summarization of data indicate at least one risk behavior observed more in male, alcohol consumers' and drugs abusers' compared to their counterparts [8].

Eighty eight point one percent of the respondents have agreed that sexual intercourse should not be committed before marriage. A large number $(82.5 \%)$ required screening for HIV as a prerequisite for marriage. Ninety seven point two percent volunteered to be tested for HIV if requested and $89.9 \%$ agreed for posttest counseling. Of all the respondents, $84(14.9 \%)$ reported to have had sexual intercourse at least once in the past. Ten $(11.9 \%)$ of the sexually active respondents had sex with commercial sex workers (CSW) in the past six months and $9(10.7 \%)$ had contracted sexually transmitted diseases (STDs) [1]. About one in four, 686 (24.8\%) never married in-school adolescent respondents reported pre-marital sexual debut of these $28.8 \%$ were males and $14.7 \%$ were females $(\mathrm{p}<0.001)$. Pre-marital sexual debut was more common among adolescents who had their parents in urban areas (AOR and $[95 \% \mathrm{CI}]=1.42[1.17-$ 1.73]), who received higher pocket money per month (AOR and $[95 \% \mathrm{CI}]=1.56[1.19-2.04])$, who perceived low selfeducational $\operatorname{rank}(\mathrm{AOR}$ and $[95 \% \mathrm{CI}]=1.89[1.07-3.34])$ and who lived in rented houses (AOR and $[95 \% \mathrm{CI}]=1.32[1.03$ 1.70]). The females and those who were less influenced by external pressure were more protected against pre-marital sexual debut $(\mathrm{AOR}$ and $[95 \% \mathrm{CI}]=0.44[0.35-0.56 ; 0.62$ [0.52-0.74, respectively]) than their counterparts [9].

Majority of the students 619 (59.4\%) who ever had sexual intercourse started sex during high school level except for Gondar university where up to $59.5 \%$ of the students started sex after joining university. The proportion of students who started sex during high school ranges from $58.6 \%$ in Haromaya University to $75.5 \%$ in Jimma University. Out of the different reasons mentioned for starting sex true sexual desire, boy/girlfriend's Pressure, to maintain relationship, and peer's pressure were the top most reasons sequentially. Substance use had statistically significant association with ever having sexual intercourse in mostof the universities (Jimma, Mekele \& Haramya universities). Attending night club had statistically significant association with ever having sexual intercourse among respondents from Jimma Haromaya Universities. Having monthly income of $>300$ Birr had a significant association among respondents from Hawasa University (7). While most of male participants had their first sexual experience before coming to the University, $(320,85 \%)$, only $(31,42 \%)$ of females reported the same. Among those reporting ever having sex, $41.2 \%$ reported having two or more lifetime sexual partners, $43.2 \%$ and $17.7 \%$ among males and females, respectively [3]. Last but not least is a research which is done in dire dawa university where by Majority, 313(87.9) of sexually active participants started sexual intercourse before entering to the university [10].

\subsection{Alcohol and Drug Abuse}

For the past several decades, adolescent alcohol use has become a source of alarm at many levels of society. Researchers have explored both the prevalence and etiology of adolescent alcohol use, concluding that prevalence is high among middle and high school students in the United States. Adolescence is the age period during which alcohol and drug use are typically initiated. Community survey data indicate that most adolescents have tried alcohol (e.g. 51\% in 8th grade, $80.3 \%$ in 12 th grade). Heavy episodic drinking (also known as binge drinking), defined as five or more drinks in one episode, is reported by over $30 \%$ of 12 th-graders in any two-week period.

These statistics have been stable for several years, indicating that alcohol experimentation is normative and binge drinking common among adolescents. However, simply because adolescent drinking is developmentally normative does not mean that it is without clinical or public health significance. Alcohol remains the most widely used substance among adolescents and studies show that the proportion of youth who use alcohol increases during adolescence. Alcohol use among adolescents follows a sequential pattern, with experimentation beginning in early adolescence and progressing to peak use in the late teens and early 20s, followed by a leveling off of usage after that. Adolescent alcohol use (particularly heavy use) is associated with many negative outcomes. Alcohol dependent adolescents have poorer neuropsychological performance and are more sensitive to learning and memory impairments produced by alcohol exposure. Adolescent alcohol use may interfere with the development of social, coping, and related skills needed for effective social functioning in late adolescence and early adulthood.

The association between adolescent alcohol consumption and risky sexual behavior is also of public health importance. Adolescent alcohol use is linked with earlier initiation of sexual activity, more frequent sexual activity, and less frequent condom use. According to the YRBS, 34\% of students nationwide reported being sexually active currently. Of those students, $23 \%$ had drunk alcohol or used drugs before last sexual intercourse [14]. For many adolescents, the adverse sexual consequences that occur while drinking include unplanned sexual intercourse, multiple partners, and inconsistent condom use.

Given the prevalence of alcohol and drug consumption among adolescents and the potential serious consequences stemming from the misuse of it, it is important to identify and understand the factors that put adolescents at risk for engaging in this behavior. Families are considered to carry substantial weight for the introduction of risk and/or protective factors into an adolescent's life; hence, the context of the adolescent's family is considered the primary social influence in this study. Although peers are a vital part of an adolescent's life, the family continues to influence the decisions made throughout adolescence as the primary provider of nurturance. Parental monitoring is a critical 
protective factor in adolescent risk-taking behavior. When parents demonstrate concern for their adolescents, set distinct rules, and express interest in their adolescents' whereabouts, risky behavior in adolescents decline [15].

\subsection{Condom Use}

A research was done at Agaro high school to see determinants of condom use by students and among students, who participated, one fourth of them had sexual exposure and it was higher among males (32.6\% Vs $13.8 \%$ ). Males also start their sexual activity earlier than females. Mean age for sexual debut was $(16.74 \pm 2.01)$. The prevalence of condom use was higher than the study done at Gondar College of Medical Sciences and Agaro High School in 1994 G. C, which may be explained by the time difference and the effect of continued information dissemination through different means. Students of Agaro High School had multiple sexual partners $(44 \%)$ compared to other studies by Kidane and colleagues and Beyene et al. This may be attributed to a higher rate of promotion of condom among adolescents when compared to interventions directed towards limiting number of partners. In this study, males intended to use condoms more than their female counter parts, despite higher proportion of males involved in other (like contact with commercial sex workers, having multiple sexual partner) high-risk sexual behaviors. Peer education and social influences play a major role in changing behavior. Selfefficacy showed association with intention to use condom among males but it was not found to be a predicator. The factors of HIV preventive behaviors identified should be considered in the developments of education intervention programs [11].

Out of the 84 sexually active respondents, 46 (54.8\%) did not use condoms. From the 38 respondents who used condoms, only $26(68.4 \%)$ used always while the other 12 $(31.5 \%)$ reported that they use condoms only some times. (1) Ninety-four $(31.3 \%)$ students had a history of sexual intercourse, and $70.2 \%$ of these students had used a condom. However, only $43.9 \%$ said they used condoms consistently [12].

\section{Methodology}

\subsection{Study Design}

A Cross sectional study design was used where all high schools from both government and private was incorporated and the study was conducted from starting March 2015.

\subsection{Sampling Design and Techniques}

In a total of 17 high schools in Dire Dawa there were a total of 10869 students in grade Nine, Ten, Eleven and Twelve of which 2957 (1561 \& 1396) were male and female respectively) were in Private school and 7912 (4550 \& 3362 were males and females respectively) were in government schools [16]. Then the strata was government and private schools. The total sample size was calculated proportionally allocated to each stratum meaning government and private schools were proportionally allocated to each school enrollment size within each stratum. This was all grades inclusive i.e. Grade 9, Grade 10, Grade 11 and Grade 12). Students were finally selected systematically from the four grades and all sections by obtaining their list from the respective schools. A list with all schools in the city is obtained from the Dire Dawa administration education bureau.

The HIV prevalence of 1.1 percent from a study conducted on high school students in Gondar city was used as the expected HIV prevalence finding along with 95 percent level of confidence and a 2 percent margin of error [2]. Based on these parameters and total enrollment size of high school student in Dire Dawa city, 10,869 the total sample size calculated is as follows [17]:

$$
n_{0}=\frac{Z_{\alpha / 2}^{2} p q}{d^{2}}=1087
$$

Where $Z \alpha / 2=1.96$, (p) $=0.13$ prevalence of sexual practice and (d) margin of error. After adjusting this total figure to the population size the sample size will be 989. Proportional allocation to each school based on their enrollment size, for both Government and private schools was made. Finally, list of enrolled students were obtained from each school and students and finally selected using systematic sampling from the sampling frame.

\subsection{Study Variables}

Dependent Variable: Ever had sexual intercourse, Current sexual intercourse, unsafe sexual practices, drug use, alcohol use.

Independent Variables: are socio-demographic (Age, Sex, Grade and others), sexual history and Behavior (Age at first sex, Reason for sex and others), history of Sexually transmitted disease (ever had one), substance and Alcohol use (ever used one of the different drugs, having sex soon after the drug, intention to stop and others), knowledge, Opinion and Attitude on HIV/AIDS (Means of transmission, tendency of the students to acquire the disease and others), school activities and Communication (being a member of AIDS club of their school, their source of information about HIV and others) and parental monitoring.

Inclusion and exclusion criteria: Actively enrolled regular students from both government and private schools whose age is greater than 15 years and are willing to give consent and participate in the study was included.

\subsection{Data Source and Collection}

The study used primary data collected from actively enrolled regular students of both the government and private schools. It included students who were in grade range of Nine to Twelve.

Questionnaire: All participants were asked to complete the questionnaire prepared for the study. The questionnaire was translated in to Amharic, Afan Oromo and Somali. It was 
take about an hour to complete. Variables related to parental monitoring was managed using likert scale in 1 up to 5 rating scale.

\subsection{Data Processing and Analysis}

Prior to data feeding the questionnaires was checked and edited for any errors. Data was fed in to CsPro 5.0 after which cleaning and analysis was carried out by exporting to SPSS 21 . The data analysis was undertaken using descriptive methods and binary logistic regression model to identify determinants of ever having sex and unsafe sex.

Descriptive data analysis was done for variables such as Socio-demographic characteristics, Sexual Practices (Sexual Experiences (Pornography, Transactional sex, Multiple sexual partners, Homosexual), Current sexual experience, Condom Use, Consequence of unsafe sex), Substance use, Perception and knowledge about HIV, Source of information and preferred intervention, HIV testing history and current test result. The Mean, Frequency, Percentages, Cross tabulation and Chi-square test of association will be used.

Bivariate analysis: bivariate analysis was carried out to see which of the independent variables/determinants was related with the response variable i.e. unsafe sexual practices. This gave us a direction as to which of the predictors should be included in the model. Accordingly predictors such as age, sex, substance use, accommodation, watching Pornography, Monthly income, parental monitoring and the above mentioned response variables was checked by the bivariate analysis.

Logistic Regression Model:

The study used binary logistic regression model using unsafe sex as a target dependent variable and predictors such age, sex, monthly income, grade, substance use, accommodation, watching pornography. The model uses Maximum likelihood estimation to get the parameters of the population and Wald statistic to test the significance of the parameters. The goodness-of-fit of this model is assessed by Deviance the model.

\section{Results and Discussion}

\subsection{Socio-demographic Characteristics of Students}

The table (Table 1) below presents the age, sex, grade level, current residence of participants and type of school that they have previously attended. Based on this the table clearly depicts that from the total of 840 participants $456(56.7 \%)$ are males and the rest $364(43.3 \%)$ are females which shows that nearly equal number of male and female students are participated in this research.

The table also shows that the age limit of participants totally ranges between ages 14-18. More specifically the age range of 14 to 16 holds the lions share position which is about $504(72 \%)$ of the total sample population and the remaining $196(28 \%)$ of the respondents are found in the age ranges of 17-18. As it is also indicated in the table above, the largest number of participants came from grade nine which holds $308(36.7 \%)$ of the total population followed by grade ten that is $280(33.3 \%)$ and the least number of respondents are from grade twelve which is only $112(13.3 \%)$. This is due to the fact that there are large number of students in grade nine and ten both in government and private schools. The participants were also asked about with whom they are living with in order to see what does parental monitoring and their involvement in risky behaviors seems like. Based on this as it is clearly shown in the table 1 below nearly all or 784 (93.3\%) of participants are currently living with their family and only $56(6.7 \%)$ of participants are responded as they are living away from their family.

Finally the participants are also requested to reply on the type of school (whether public or private) that they have attended before the current school that they are attending. In light of this the table above shows that 728 (96.3\%) of the participants have attended public schools prior to the current school that they are attending and only $28(3.7 \%)$ of the respondents responded that they followed their earlier education in private schools.

Table 1. Socio demographics characteristics of Dire Dawa high school Students participated in YRBS study, Dire Daw, Ethiopia 2016.

\begin{tabular}{llll}
\hline Category & Variable & Frequency & \% \\
\hline \multirow{4}{*}{ Sex } & Male & 476 & 56.7 \\
& Female & 364 & 43.3 \\
& Total & 840 & 100.0 \\
Age & $14-16$ & 504 & 72 \\
& $17-18$ & 196 & 28 \\
& Total & 700 & 100.0 \\
Grade level & $9^{\text {th }}$ & 308 & 36.7 \\
& 10 th & 280 & 33.3 \\
& $11^{\text {th }}$ & 140 & 16.7 \\
& $12^{\text {th }}$ & 112 & 13.3 \\
Currently living with & Total & 840 & 100.0 \\
& With family & 784 & 93.3 \\
& Away from family & 56 & 6.7 \\
Type of school attended & Total & 840 & 100.0 \\
& Public & 728 & 96.3 \\
& Private & 28 & 3.7 \\
& Total & 756 & 100 \\
\hline
\end{tabular}

\subsection{Sexual Practices}

The result in table 2 below depicts that $364(76.5 \%)$ of male and $28(8.3 \%)$ of female students with the total of 392 $(48.3 \%)$ number of respondents replied yes for the item on the questionnaire that whether they ever committed sexual intercourse or not and $112(23.5 \%)$ of male and $308(91.7 \%)$ of female students with the total number of $420(51.7 \%)$ of participants replied no to the same question. A similar study (L. Richter et. al., 2013) conducted on teenagers from three African countries (South Africa, Zimbabwe and Tanzania) by taking 11,206 sample found that 914 (74.2\%) and 1206 $(84.9 \%)$ of the male respondents from Zambia and Tanzania respectively had sexual intercourse. From the females respondents 1365 (83.4\%) from Zambia and 1546 (93.8\%) from Tanzania had reported to have committed sexual intercourse. This results from these African countries indicated similar pattern among male students but there is 
lower figure for females respondents form this study. Another study conducted in Ethiopia on sexual risk behaviors and condom use among secondary schools in Ethiopia found that one third $(33.3 \%)$ of the students reported to have had sexual intercourse [18].

A study conducted by Family guidance and association of Ethiopia (2003) on adolescent sexuality among out-ofschools teenagers found that $71.9 \%$ of the boys and $71.4 \%$ of the girls have had sexual experience. In support of this finding a study conducted in North Gondar to assess the prevalence of risky sexual behavior and associated predisposing factors among in-school and out-of-school youths found that about $49.7 \%$ were found to be sexually active. A study conducted by in Nekemte to assess premarital sexual practice among high school students found a very high level of pre-marital sexual practice (i.e. $70.3 \%$ for males and $29.7 \%$ for females) [19]. The participants were also asked about the reason why they have committed sexual intercourse and their response as it is clearly shown in the table 2 below, $203(55.8 \%)$ of male and $26(92.9 \%)$ female participants with the total number of 229 (58.4\%) replied that they were influenced by their personal desire to have sexual intercourse. It is also indicated that $113(36.5 \%)$ of male and $2(7.1 \%)$ of female respondents with the total of $135(34.4 \%)$ responded that they have been involved in sexual relationship due to peer pressure. From this we can also conclude that males are more likely to be influenced by peer pressure than females in a relation to the involvement of sexual relationships and the least number of participants and only male participants $(28,7.7 \%)$ involved in sexual relationships due to alcohol intoxication.

Another similar study found that $35.2 \%$ of sexually engaged teenagers were due to peer pressure which supports the finding of this study [20]. Another study conducted in Addis Ababa preparatory schools by Azeb to identify risk factors of unsafe sexual behavior found that $49.45 \%$ of males and $36.46 \%$ of females found that students had pressure from friends/peers to have sex [21]. In this same study it was reported that $37.74 \%$ of students had their first sex due to their physical pleasure.

Table 2. Sexual practices among Dire Dawa high school Students, Dire Dawa, Ethiopia, 2016.

\begin{tabular}{|c|c|c|c|c|}
\hline Variable & & Male (\%) & Female (\%) & Total (\%) \\
\hline \multirow{2}{*}{ Ever had sex } & Yes & $364(76.5)$ & $28(8.3)$ & $392(48.3)$ \\
\hline & No & $112(23.5)$ & $308(91.7)$ & $420(51.7)$ \\
\hline \multirow[t]{2}{*}{ Age at first sex } & Mean age (SD) & $16.6(+0.84)$ & $15.63(+0.9)$ & $18.26(+2.6)$ \\
\hline & Personal desire & $203(55.8)$ & $26(92.9)$ & $229(58.4)$ \\
\hline \multirow[t]{3}{*}{ Reason for having sex } & Peer pressure & $113(36.5)$ & $2(7.1)$ & $135(34.4)$ \\
\hline & Influence of alcohol & $28(7.7)$ & 0 & $28(7.1)$ \\
\hline & Boy/girl friend & $364(100)$ & $26(92.8)$ & $390(99.5)$ \\
\hline \multirow{2}{*}{ With whom did you first have sex? } & Other & - & - & - \\
\hline & Same age & $364(100)$ & 0 & $364(92.9)$ \\
\hline \multirow[t]{2}{*}{ Age of the person you had sex for at the first time } & 5 - 10 years older & 0 & $28(100)$ & $28(7.1)$ \\
\hline & Greater than 10 years & - & - & $39(8)$ \\
\hline \multirow{2}{*}{ Where did you start sex? } & Before secondary school & 0 & $28(100)$ & $28(7.1)$ \\
\hline & At secondary school & $364(100)$ & 0 & $364(92.9)$ \\
\hline Total number of life time sexual partners & Only one & $28(7.7)$ & $11(39.3)$ & $39(9.9)$ \\
\hline Having sex with same sex & No & $586(97.0)$ & $237(98.3)$ & $823(97.4)$ \\
\hline
\end{tabular}

In a relation to the person that the respondents' first committed sexual intercourse almost all males (i.e. 364, $100 \%$ ) replied that they have committed with their girlfriends and $26(92.8 \%)$ of all females replied that they had sexual intercourse with their boyfriend and $2(7.1 \%)$ stated that they had sex with businessmen.

Regarding mean age at first sex it was $16.6(+0.84)$ and $15.6(+0.9)$ years for males and females respectively which indicates that females are more likely to start sex early than their male counterparts. Similarly among high school students in Gondar city found that the mean age at fist sex is $17(+1.3)$ for males and $16.4(+1.6)$ for female leading us to conclude that more females engage earlier in sex than males [2]. Similarly another study conducted a study in and around Dessie to identify age at sexual initiation among the youth and found that the mean age at first sex was $16.5(+2.11)$ for rural and $17.2(+2.32)$ for urban youths [13].

The table also depicts the age of the person the participants had sex with for the first time. Based on this the largest number of male participants (i.e., 364, 100\%) responded that they committed sexual intercourse with girls who are found at the same age where as contrary to this there is no single girl who committed sexual intercourse with boys who are found at the same age rather $28(100 \%)$ of female participants replied that they had first sex with people who are by 5-10 years elder than them. Azeb has conducted similar study in Addis Ababa preparatory schools to identify risk factors of unsafe sexual behavior where she found that $25.3 \%$ of males and $71.2 \%$ of females reported that their first sexual partner was at an older age than them [21].

The table also indicates that $28(100 \%)$ of female participants started to practice sexual practice before entering in to the secondary school and $364(100 \%)$ of male participants replied that they started sexual practice at secondary school level. This means that girls started sexual practice earlier than boys and this goes in agreement with the 
mean age at first sex where female were found to start sex earlier.

Concerning to the number of sexual partners that they had $336(92.3 \%)$ of male participants and $17(60.7 \%)$ of female participants responded that they had 2 to 5 life time sexual partners. Additionally 11 (39.3\%) of females had sexual experience with only one partner. Similarly in her study to identify risk factors of unsafe sexual behavior among Addis Ababa preparatory schools Azeb has $60.8 \%$ of the students had sexual intercourse with more than one person [21]. In another study conducted in Gurage Zone among preparatory school students it was found that among sexually active ones $70.5 \%$ had two and more sexual partners [11].

\subsection{Unprotected Sex Among Students}

In relation to the use of condom, the figure below indicated that $224(62.2 \%)$ of male and $3(11.1 \%)$ female participants with the total number of $227(58.7 \%)$ replied to have used condom during sex. In a study (Belaineh G. et. al., 2004) conducted among Agaro high school students 55.7\% of males and $50 \%$ of females with a total of $54.4 \%$ of students reported to have used condom at least once. In another study conducted among high school students in Gondar it was found that among sexually active ones nearly $54.8 \%$ of the respondents did not use condom [2].

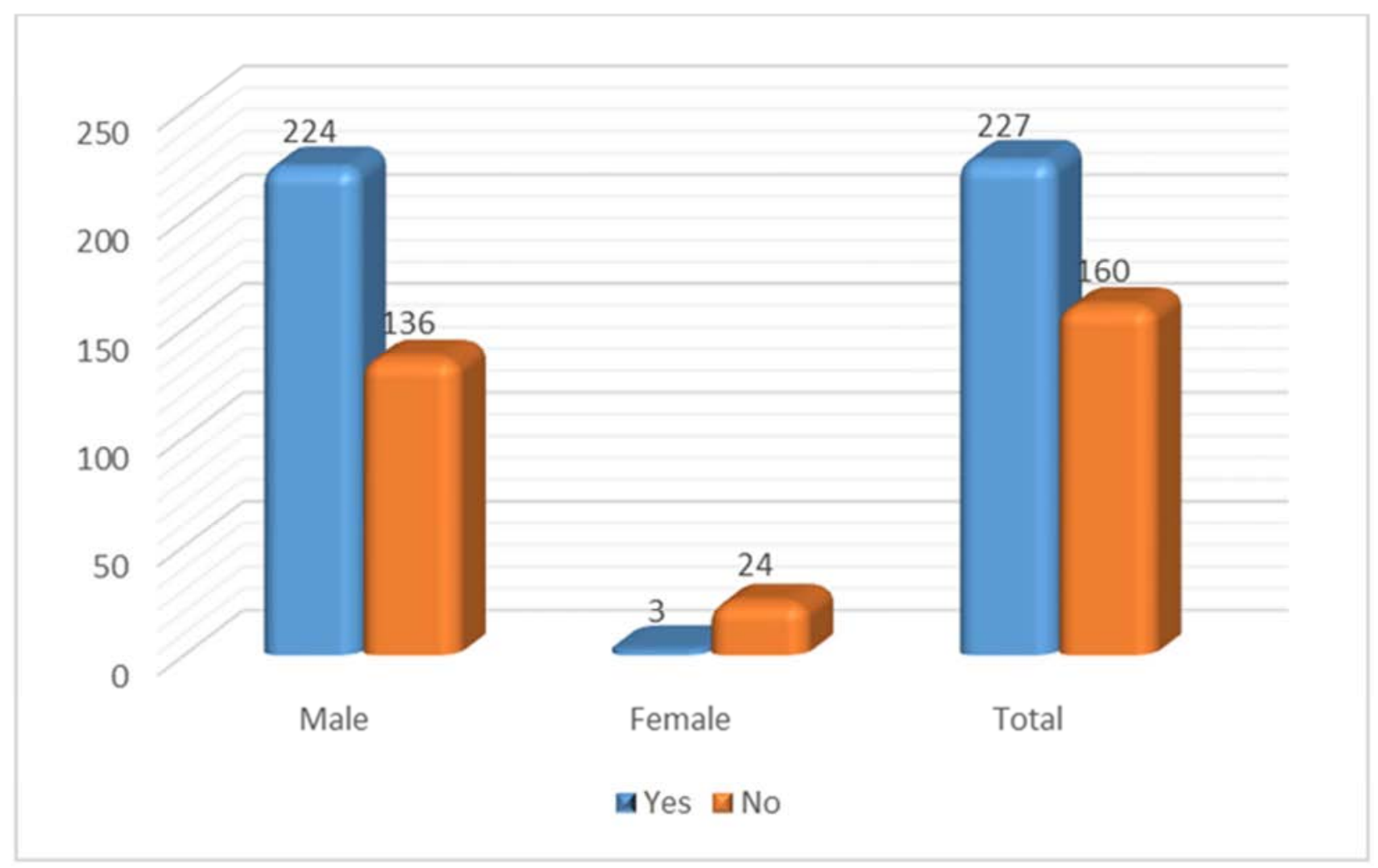

Figure 1. Condom use among Dire Dawa high school students, Dire Dawa, Ethiopia, 2016.

\subsection{Determinants of Risky Sexual Behavior}

The binary multiple logistic regression model was fit after undertaking bivariate association test between risky sexual behavior and the candidate predictors. Students that are using substance and alcohol were two times more likely $[\mathrm{AOR}=2.098,95 \% \mathrm{CI}(1.386,3.17)]$ to practice unsafe sex than students who don't use substance and alcohol. Male students were thirteen times more likely to have unsafe sexual practice than their female counterparts $[\mathrm{AOR}=13.176$, 95\% CI $(3.894,44.586)]$. Additionally students that do not watch pornography were $90 \%$ less likely to have unsafe sex in comparison to those watching pornography $[\mathrm{AOR}=0.098$, $95 \%$ CI $(0.023,0.419)]$. Furthermore in terms of monthly expense, the model revealed that students with more than five hundred birr monthly expense were $15 \%$ less likely to have unsafe sex compared to students with monthly expense of less three hundred birr [AOR $=0.85,95 \%$ CI $(0.025,0.289)]$.

In a study (Likawunt S. \& Mulugeta T., 2012) conducted to identify determinants of substance use and risky sexual behavior it was found that sex, watching pornography and alcohol use were significantly associated with unsafe sex. Female respondents $[\mathrm{AOR}(\mathrm{CI})=0.9(0.5,1.58]$ were less likely, pornography viewers $[\mathrm{AOR}(\mathrm{CI})=2.15(1.16,3.95)]$ were more likely and alcohol users $[\operatorname{AOR}(C I)=2.8(1.65$, 5.02] were more likely to engage in unsafe sexual risk practices. 
Table 3. Factors associated with unsafe sex among Dire Dawa high school Students, Dire Dawa, Ethiopia, 2016.

\begin{tabular}{|c|c|c|c|c|}
\hline \multirow[t]{2}{*}{ Variables } & \multicolumn{4}{|c|}{ Unprotected sex } \\
\hline & Yes & No & AOR (95\% CI) & P-value \\
\hline \multicolumn{5}{|l|}{ Sex } \\
\hline Male & $224(98.7)$ & $136(85)$ & $13.176(3.894,44.586)$ & 0.000 \\
\hline Female (R) & $3(1.3)$ & $24(15)$ & & \\
\hline \multicolumn{5}{|l|}{ Substance \& alcohol use } \\
\hline Yes & $102(44.9)$ & $101(63.1)$ & $2.098(1.386,3.17)$ & 0.000 \\
\hline No $(R)$ & $125(55.1)$ & $59(36.9)$ & & \\
\hline \multicolumn{5}{|l|}{ Currently living with } \\
\hline With family & $198(87.2)$ & $135(84.4)$ & $0.791(0.444,1.41)$ & 0.426 \\
\hline Away from family (R) & $29(12.8)$ & $25(15.6)$ & & \\
\hline \multicolumn{5}{|l|}{ Watched pornography } \\
\hline Yes $(\mathrm{R})$ & $201(88.5)$ & $158(98.8)$ & & \\
\hline No & $26(11.5)$ & $2(1.3)$ & $0.098(0.023,0.419)$ & 0.002 \\
\hline \multicolumn{5}{|l|}{ Monthly expense } \\
\hline$<=300 \operatorname{birr}(\mathrm{R})$ & $198(87.2)$ & $135(84.4)$ & & \\
\hline $300-500$ birr & $26(11.5)$ & $1(0.6)$ & $17.727(2.377,40.204)$ & 0.005 \\
\hline More than 500 birr & $3(1.3)$ & $24(15)$ & $0.85(0.025,0.289)$ & 0.000 \\
\hline
\end{tabular}

\section{Conclusion and Recommendations}

The result of this study shows that female start sexual practice earlier than their male counterpart and nearly half of the students are engaged on unsafe sex. Additionally the majority of students are susceptible to risky behaviors like unsafe sex and drug and alcohol abuse. More specifically students that are using substance and alcohol were nearly four times more likely to ever practice sexual intercourse than students who don't use substance and alcohol. Similarly Students that do not watch pornography were less likely to ever practice sex compared to those watching pornography and additionally female students were less likely to ever practice sex than their male counterparts. Furthermore the model indicated that students with monthly expense between three and five hundred birr are less likely to ever have sex. Therefore Ministry of health and related stakeholders should focus on high schools students on their intervention actions. Currently there are many places around schools that provide an opportunity for students to take various kinds of harmful drugs and pave ways for students to be involved in different risky behaviours therefore concerned bodies should work aggressively to make communities safe and supportive for youth development. School curriculums should be revised periodically to see the gaps remained and schools should provide students with high quality education which can address all domains of students' development and provide students opportunities to build social and emotional competence.

\section{Acknowledgment}

We would like to express our profound gratitude to Dire Dawa University for funding this study. We would also like to thank Dire Dawa city education bureau and high schools for their cooperation in the course of this study.

\section{References}

[1] Gashaw Andargie, Afework Kassu, Feleke Moges, Yigzaw Kebede, Molla Gedefaw, Fisseha Wale, Atnaf Alem, Berhanu Andualem Solomon Adungna (2007): Low prevalence of HIV infection, and knowledge, attitude and practice on HIV/AIDS among high school students in Gondar, Northwest Ethiopia Ethiop. J. Health Dev. 21 (2): 179-182.

[2] Bio-Behavioral Study among Dire Dawa University Students April 2013.

[3] Abreham A.(2011). Risky Sexual Behaviors and Predisposing Factors among Ethiopian University Students.

[4] Gabre, Solomon (1990). Sexual Behavior and Knwoldge of AIDS and other STIs: A survey of senior high school students.

[5] Lemessa Oljira, Yemane Berhane and Alemayehu Worku (2013). Assessment of comprehensive HIV/AIDS knowledge level among in-school adolescents in eastern Ethiopia By Journal of the International AIDS Society.

[6] SUPREME Consult PLC (2012). Education Sector Response to HIV and AIDS Learning from good practices in Ethiopia.

[7] Yitayal Shiferaw, Agersew Alemu, Amanuel Girma, Afera Getahun, Andarge Kassa, Alemayehu Gashaw, Abebe Alemu, Takele Teklu and Baye Gelaw (2011). Assessment of knowledge, attitude and risk behaviors towards HIV/AIDS and other sexual transmitted infection among preparatory students of Gondar town, north west Ethiopia. BMC Research Notes.

[8] Oljira L, Berhane Y, Worku A (2012). Pre-marital sexual debut and its associated factors among in-school adolescents in Eastern Ethiopia. By. BMC Public Health.

[9] Birhan Mengistu (2009). HIV Prevalence and Associated Factors among Students of Dire Dawa University, Eastern Ethiopia.

[10] Belaineh G., Demeke A., Kora T. (2004). Determinants of Condom Use among Agaro High school Students using Behaioural Models. Ethiopian Journalof Health Dev. 
[11] Thanavanh B, Harun-Or-Rashid M, Kasuya H, Sakamoto J. J. (2013). Knowledge attitudes and practices regarding HIV/AIDS among male high school students in Lao People's Democratic Republic. Int AIDS Soc.

[12] Fekadu M. \& Alemayehu W. (2009). Age at sexual initiation and factors associated with it among youths in North East Ethiopia.

[13] Center for Disease Control and Prevention (2006). Disease profile, National Center for HIV/AIDS, Viral Hepatitis, STD and TB Prevention.

[14] Li, X., Feigelman, S., \& Stanton, B. (2000b). Perceived parental monitoring and health risk behaviors among urban low-income African American children and adolescents. Journal of Adolescent Health.

[15] Dire Dawa Education Bureau (2005). Education Statistics Annual Abstract.
[16] William Cochran (1977). Sampling Techniques. Third Edition.

[17] Adamu R, Samuel M and Ingidushet S. (2003). Patterns and Correlates of Sexual Initiation, Sexual risk behaviours and Condom use among secondary school students in Ethiopia.

[18] Assefa Seme and Dessalegn Wirtu (2006). Premarital Sexual Practice among School Adolescents in Nekemte Town, East Wollega.

[19] Frehiwet Alebachew (2006). Behaviour Change Communication and the Response of Young Adults: The Case of Ethiopia.

[20] Azeb Amha (2009). The morphosyntax of negation in Zargulla. In L. Wetzels (ed.) The Linguistics of Endangered Languages: contributions to morphology and morphosyntx. 